\title{
Experimental research on high-temperature properties of concrete coarse aggregate
}

\author{
Author:1,Wang Li ,2Fu Libin 3Li Chenliang \\ Huanghe Science and Technology College
}

Keywords:concrete, coarse aggregate, high temperature mechanical properties

Abstract: Theratio of the thickness of the aggregate accounted for roughly $70 \%$,andit's performance is good or bad has a direct impact on the strength of concrete, In this paper, the heating device with coarse aggregate of concrete by varying degrees of high temperature treatment, study the change of its physical and mechanical properties, for the study of aggregate on concrete degree of preparing high temperature mechanics performance influence.

\section{First, thetest object}

By common coarse aggregate concrete with different degrees of heat insulation treatment, the determination of its physical and mechanical properties observed mass loss, color changes, and changes in surface morphology crushing indicators, study its performance in high-temperature study of concrete prepare.

\section{Second, thetest equipment}

1, HZCS-01IPCautomatic fire simulation test systemandautomatic temperature control heating system:Class1equipment as shownin Figure 2.
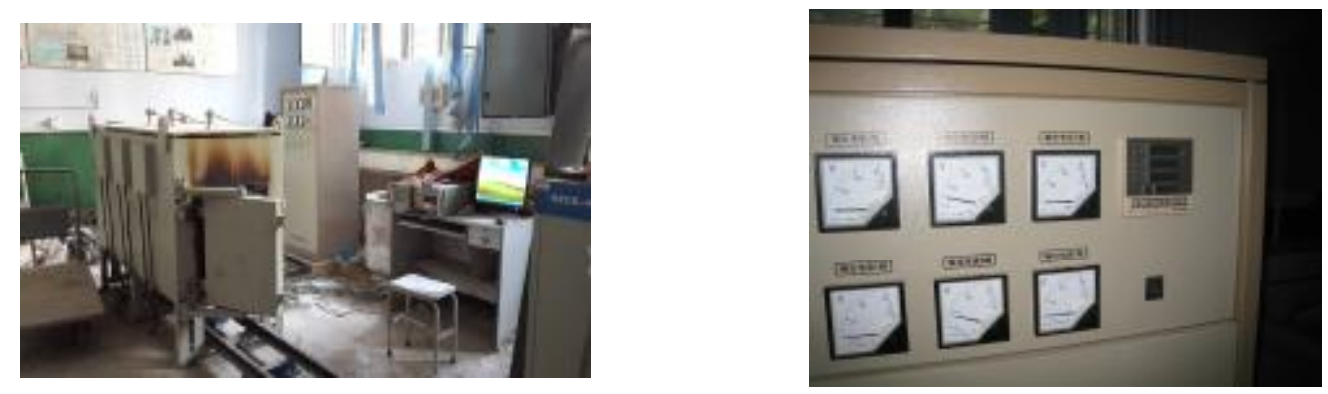

Figure1: HZCS-01IPCautomatic fire simulation test system of FIG.

Figure2:Automatic temperature control heating system control cabinet

2, crushing value tester,standard square hole sieve sand and weighing instruments, standard sandsieve,sieve shaking blast oven and electric machines. 


\section{Third,test procedure}

1. Sample preparation: In this experiment, all from Xinhai gravel concrete mixing station, select the nominal size class5 $-20 \mathrm{mmconcrete}$ with calcareous gravel, gravel batch in line with national standardsGB / T14685-2011 "constructionwith gravel, pebbles, "the technical requirements of concrete with coarse aggregate. According to standard methodsgravel placed blast oven dried to constant weight, random samples drawn from5partsandeach5kgbe numberedA, B, C, D, E and make a mark.

2, the high temperature treatment of the sample: the number of B, C, D, E,respectively, through the grave 1HZCS-01IP Cautomatic fire simulation test system $300^{\circ} \mathrm{C}, 400^{\circ} \mathrm{C}$, high temperature of $500{ }^{\circ} \mathrm{C}$ and $600{ }^{\circ} \mathrm{C}$. To ensure comparability of the sample, the heat treatment heating rate are controlled by $10^{\circ} \mathrm{C} / \mathrm{min}$.

3, according to the current national standardGB / T14685-2011 "constructionwith gravel, pebbles," the sample was measured at different temperatures coarse aggregate crushing value, while measuring the mass loss temperature of each number gravel and observe its color and surface features change, make records.

\section{Fourth,experimental data analysis and conclusions}

\section{1, coarse aggregate quality}

Table1calculation processing results for mass loss at different temperatures stones situation. From the test results, in the gravel after the different treatments, there will be varying degrees of quality loss, mass loss overall modest, but with the heating temperature, mass loss increased significantly, the mass loss rate showed an increasing trend. Analysis stones after being subjected to high temperature mass reduction is mainly caused by three aspects: on the one hand stones contained high-temperature combustion of organic matter in the face will lose some quality; additional internal chemical composition stones occur under high temperature decomposition in gas may also lead to loss of quality; coupled at high temperature, the water inside the concrete containing crystalline mineral crystal water and decomposition of the components in the form of water vapor out of the volatile and so may result in loss of quality aggregates. 
Table1- Stone mass loss rate

\begin{tabular}{|c|c|c|c|c|c|}
\hline $\begin{array}{c}\text { Sample } \\
\text { No. }\end{array}$ & temperature & $\begin{array}{l}\text { Hightemperatu } \\
\text { re before } \\
\text { quality }\end{array}$ & $\begin{array}{c}\text { After the } \\
\text { mass } \\
\text { temperature }\end{array}$ & Mass loss & $\begin{array}{l}\text { Mass loss } \\
\text { Percentag } \\
\text { e(\%) }\end{array}$ \\
\hline A & $\begin{array}{c}\text { Room } \\
\text { temperature }\end{array}$ & 5000 & - & - & - \\
\hline B & $300^{\circ} \mathrm{C}$ & 5000 & 4998 & 2 & 0.04 \\
\hline C & $400^{\circ} \mathrm{C}$ & 5000 & 4994 & 6 & 0.12 \\
\hline D & $500^{\circ} \mathrm{C}$ & 5000 & 4991 & 9 & 0.18 \\
\hline E & $600^{\circ} \mathrm{C}$ & 5000 & 4986 & 14 & 0.28 \\
\hline
\end{tabular}

2 , index and crushed gravel surface features

Measuredwithinthe coarse aggregatecrushing value of certain quality air-dry state is about9.5 $-13.2 \mathrm{mmstones}$ loaded with a standard cylinder, the press machine loading, after unloading weighed sample mass $\mathrm{m}_{\mathrm{m}}$,with a pore size of 2.36 mmsieve screening crushed fines weighed sample screen $\operatorname{margin}_{\mathrm{m}} 1$,crushing index using the formula $\delta_{a}=\frac{m_{0}-m_{1}}{m_{0}} \times 100 \%$ Calculations. Crushing index is smaller, the ability to resist crushing stones stronger.

Table2-Stone crushing index and surface characteristic change table

\begin{tabular}{|c|c|c|l|}
\hline Sample & temperature & $\begin{array}{c}\text { Crushing } \\
\text { index }(\%)\end{array}$ & Color and surface characteristics \\
\hline A & $\begin{array}{c}\text { Room } \\
\text { temperature }\end{array}$ & 7.7 & Gray, bright, clean surface \\
\hline B & $300{ }^{\circ} \mathrm{C}$ & 8.8 & $\begin{array}{l}\text { Light gray, tends to dim individual red } \\
\text { surface, surface Chu Chen }\end{array}$ \\
\hline $\mathrm{C}$ & $400{ }^{\circ} \mathrm{C}$ & 9.2 & $\begin{array}{l}\text { Faded blue, the color tends to be dark, } \\
\text { increase local red particles, surface } \\
\text { Chu Chen }\end{array}$ \\
\hline $\mathrm{D}$ & $500^{\circ} \mathrm{C}$ & 12.0 & $\begin{array}{l}\text { Dark gray, touching the surface of } \\
\text { dust sense }\end{array}$ \\
\hline & 12.2 & $\begin{array}{l}\text { Gray, touching the surface of a thin } \\
\text { layer of dust particles }\end{array}$ \\
\hline
\end{tabular}

Figures3and4, respectively, before and after the numbers before and after the high temperature and crushed stone electronic picture, can clearly be seen from the figure changes color and surface characteristics of the stones subjected to high temperatures after the change. Table 2 afterthe crushing value index recorded at different temperatures and surface characteristics of the stone changes, Figure5isastone crushing index temperature curve analysis shows that both, gravel subjected to high temperature in different degrees, crushing index is rising, when the temperature 
exceeds $500{ }^{\circ} \mathrm{Creaches} 600{ }^{\circ} \mathrm{C}$,its intensity decreasing trend is slowing down, the strength of overall aggregate with the rise of temperature by gradually decreasing.
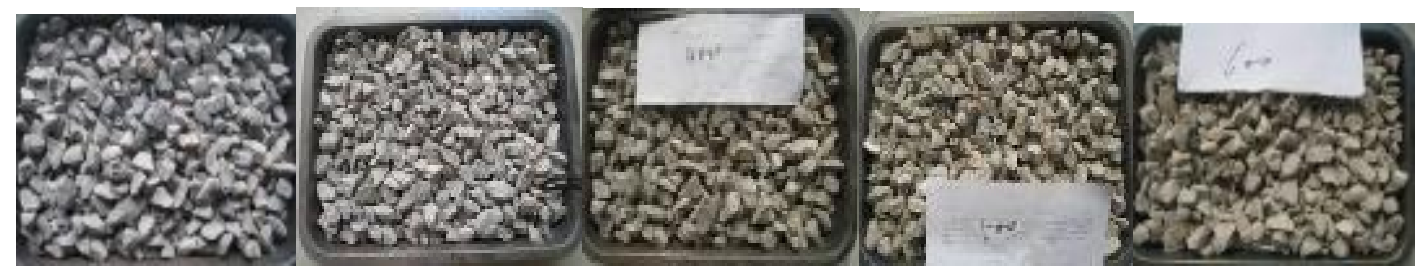

Room temperature $\quad 300^{\circ} \mathrm{C}$ $400{ }^{\circ} \mathrm{C} \quad 500{ }^{\circ} \mathrm{C}$

$600{ }^{\circ} \mathrm{C}$

\section{Figure3: Coarse aggregate after high temperature}

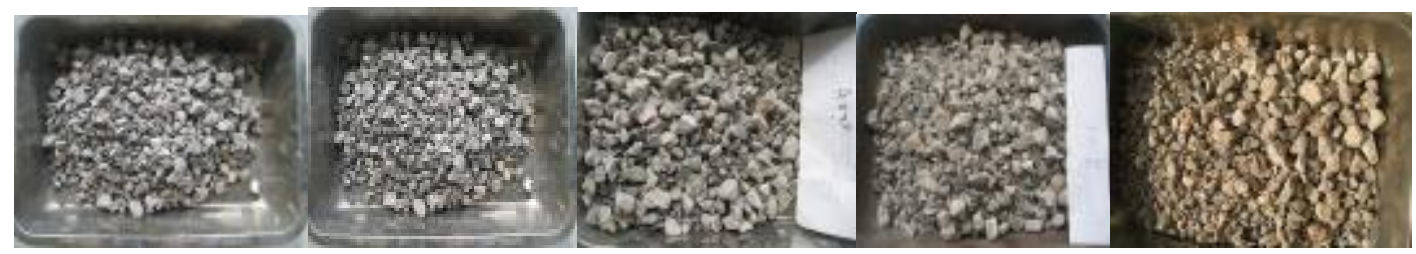

Room temperature $\quad 300{ }^{\circ} \mathrm{C} \quad 400{ }^{\circ} \mathrm{C} \quad 500{ }^{\circ} \mathrm{C} \quad 600{ }^{\circ} \mathrm{C}$

Figure4: After crushing coarse aggregate

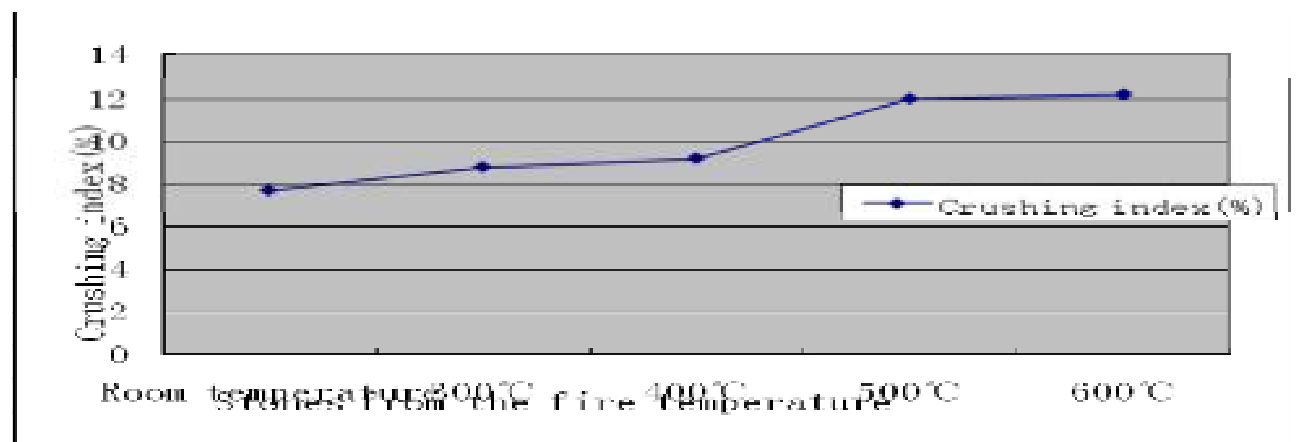

Document HOFF GC, BILODEAU A, MALHOTRA V M.Elevated temperature effects on HSC residualstrength [J] .Concrete International, 2000, 22 (4): 41-47 the discussion of loss of strength: quality limestone is larger heat capacity aggregate ratio

of high strength concrete with granite aggregate has better high temperature performance, calcined limestone aggregate, absorb heat, heat capacity and the quality is low, slowing the temperature rise inside the specimen, the strength loss reduction SLOW. Document "Experimental Thermal Analysis limestone calcination and sulphation performance," he also pointed out that, in order toCaCO3as the main component of limestone at high temperature resistance furnace, high temperature environment will generate limestone quicklime and release carbon dioxide, the main chemical reaction formula: $\mathrm{CaCO} 3 \rightarrow \mathrm{CaO}+\mathrm{CO} 2 \uparrow$, limestone begins to decompose different temperatures of about $600{ }^{\circ} \mathrm{C}$,Decomposition at About $780{ }^{\circ} \mathrm{C}$ fastest, toabout850 ${ }^{\circ} \mathrm{Cdecomposition}$ end. Integrated both concluded that due to the quality limestone aggregates larger heat capacity, when the temperature rises to600 ${ }^{\circ} \mathrm{C}$,started to decompose to absorb heat, resulting in aggregate own strength decreases 
slowing, and this just confirms the experimental data view. According to this inference, aggregatedue aftermore than $800{ }^{\circ} \mathrm{Cdecomposition}$ is substantially complete, reducing its ability to absorb heat, whether its intensity decreasing trend change it again,since the heating temperature of the test is limited, the projections conducted research until later.

Let's analyze the color and surface characteristics are also significant changes: under normal temperature stone was gray, clean and bright, with the temperature rising by the fire, faded blue, turning gray, dust particle surfaces have a sense of touch, the more color increasingly bleak, local aggregate particles appear red. For the color of dark gray Jiancheng this change, the main reason is that this experiment is calcareous stone, mainly composed of $f_{\mathrm{CaCO}} 3$. Therefore, as the temperature rises, calcareous aggregate gradually broken down, and its color has become a decomposition of calcium oxide that is an off-white color. The local surface is rendered in red may cause a small amount of iron contained in the aggregate under high temperature oxidized.

\section{References}

[1] Jianxun Dong, Yue Zhang, Zhaoxing Feng and so on. Experimental Study on Thermal Performance of Limestone High Temperature Calcination for Sulfur Fixation[J]. Thermal power generation, 2005(2)

[2] Jihong Yan. Zhishen Lin, Yunchang Hu. Experimental Studyon Compressive Strengthof Concreteafterhigh Temperature [J]China Civil Engineering Journal, fifth phase Thirty-fifth volume.

[3] Kexu Hu. Study on Adhesive Performance of Reinforced Concrete Mixed with High Temperature and Fire Resistance of Reinforced Concrete[D]. Shanghai Tongji University, February 2000.

[4] GB/T14685-2011, Gravel and Cobble for Construction[S]China Construction Industry Press, 2012.

[5] Youqun Li, Lijuan Li. Effect of High Aggregate Types on High Temperature Cracking of High Strength Concrete[J]. Concrete, April, 2011.

[6] Dagen Su. Architecture material[M]. China Architecture \& Building Press, 2002.

[7] JGJ52-2006Standard for Sand, Stone Quality and Test Methods for Ordinary Concrete[S]. China Architecture \& Building Press, 2006.

Project source:Henan Province Department of Education Project No 2017-ZZJH-336 and Henan 
province department of science and technology research projects 162102310235; Henan college students innovation and Entrepreneurship Program(2017xscxcy058). 